\title{
Research of Noise in the Unmanned Aerial Vehicle's Propeller using CFD
}

\author{
Vijayanandh R, Ramesh M, Raj Kumar G, Thianesh U K, Venkatesan K, Senthil Kumar M
}

\begin{abstract}
The major use and need of the multi-rotor $U A V$ in various fields has increased the importance to study the aerodynamics of multi-rotor Unmanned Aerial Vehicles such as the secondary flow over the blade, reduction of noise due to the propeller of the UAV, and the optimization of the design on the propeller with more blades to increase efficiency of the UAV. This paper mainly deals with the reduction of noise which is induced by the propeller. Since there is a demand for compact multi-rotor quite UAV as it has a low probability of detection using radar and infrared but as it generates high drive-line noise caused by propeller it cannot be implemented for some critical applications. As a result, an idea is launched to design a propeller with low drive-line noise levels. A methodology is developed to design a low noise as well as efficient propellers for multi-rotor UAVs. The important parameters like blade thickness, tip loss and blade loading are considered in this research. Also, the effects of propeller important parameters such as activity factor, advance ratio are considered. After the finalization of design consideration of UAV's propeller and the furthermore noise reduction methodologies also studied such as leading-edge comb, trailing edge tuft, and upper surface porosity in order to generate a perfect UAV for military applications. In order to minimize the noise produced by the propeller the idea of modifying the leading-edges is finalized. Computer-AidedDesign of base propeller and propeller with leading-edge modifications has been generated with the help of CATIA V5 and the acoustic analysis for the static base and propellers with leading-edge modifications with different velocities has been simulated using ANSYS Workbench Fluent 16.2. Finally, a propeller with the leading-edge modification has been found to induce low noise. Keywords: Noise, CFD, Decibel, Propeller, Quite UAV.
\end{abstract}

\section{UNMANNED AERIAL VEHICLE}

\subsection{Detection of Unmanned Aerial Vehicle Signature}

The implementation of the Unmanned Aerial Vehicles in various fields is due to its numerous advantages over manned aircraft. The main reason for their implementation in various fields was due to their accuracy, low weight, can fly in a no-win situation and mainly they eliminate human risk. One of the major requirements for UAV $s$ in the

Vijayanandh R, Assistant Professor Department of Aeronautical Engineering, Kumaraguru College of Technology, Coimbatore, Tamil Nadu, India.

Ramesh M, BE-Student Department of Aeronautical Engineering, Kumaraguru College of Technology, Coimbatore, Tamil Nadu, India.

Raj Kumar G, Assistant Professor Department of Aeronautical Engineering, Kumaraguru College of Technology, Coimbatore, Tamil Nadu, India.

Thianesh U K, BE-Student Department of Aeronautical Engineering, Kumaraguru College of Technology, Coimbatore, Tamil Nadu, India

Venkatesan K, ME-Student, Department of Mechanical Engineering, Alagappa Chettiar Government College of Engineering and technology, Karaikudi, Tamil Nadu, India.

Senthil Kumar M, Assistant Professor (SRG), Department of Aeronautical Engineering, Kumaraguru College of Technology, Coimbatore, Tamil Nadu, India.
Revised Manuscript Received on August 14, 2019.

performance of most of these missions is low detectability. The main parameters for detectability of the UAVs are noise levels. It is found that the major part of the noise is induced due to the blade thickness and energy loss from the tips of the blades from the propellers. The modification made in the base propeller includes reducing blade thickness by modifying the leading edge of it without affecting the design to a larger extent.

\subsection{Propeller and its noise}

The blade used here has the profile of Clark-Y airfoil. For designing a propeller in CATIA, a computer script was generated for any 2 or 3 blade propellers. The inputs parameters such as activity factor, advance ratio, efficiency and some propeller characteristics are used as an input in text files that describe the propeller geometry. The propeller is modeled using CATIA V5 and can be used for simulation. A comparative acoustic analysis has been done between a base propeller and the propellers with leading edge modifications. The static propeller acoustic analysis with different velocities provided good results and laid a foundation for future work. The acoustic analysis is done numerically but it is recommended that the test should be conducted experimentally in an anechoic facility, where noise from the external sources is eliminated. The recent developments in unmanned aerial vehicles (UAVs) demand a design for quitter unmanned aerial vehicle. A design methodology is developed to make quite propellers for electric UAVs. The design modification on the leading edge of the propeller is made and analyzed.

\subsection{Reduction of Propeller noise}

Minimizing the noise from the UAVs helps implementation of them in various new fields. In order to minimize the noise from the propellers the methodology used is to modify the leading edge of the propeller. This modification is inspired by the characteristics found on the feathers of certain owls. The modifications could successfully reduce the noise while maintaining the considerable levels of thrust over a wide range of rpm.

\section{CONCEPTUAL DESIGN OF VARIOUS REFERENCE COMPONENTS}

\subsection{Base Propeller}

Base propeller shown in Fig. 1 is which, currently used in the industry. The base propeller is a just a hub fixed with

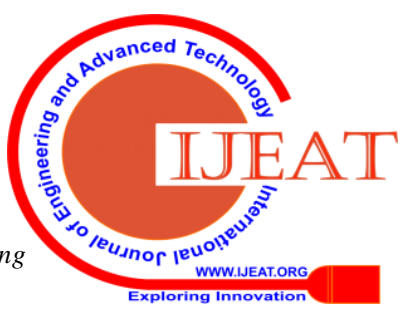


two scaled down wings. It is highly used because of its aerodynamic design, less weight etc. Even though it is aerodynamically suitable for many applications it produces high noise which restricts the use of UAVs in military applications where the mission has to done very quietly

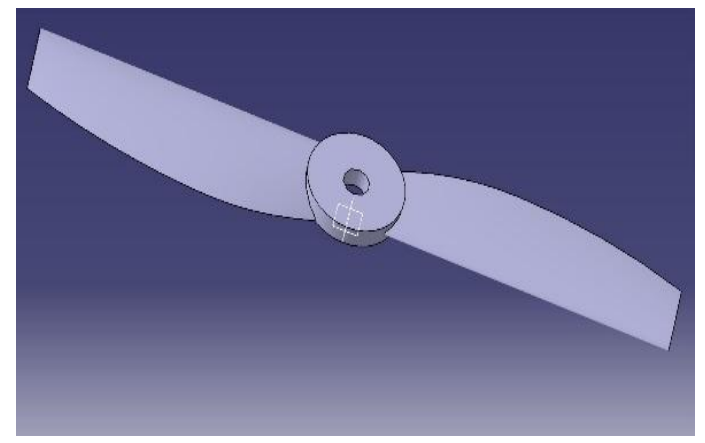

Fig 1. Normal Propeller

\subsection{Modification 1 - SAW tooth}

Saw tooth like cut shown in Fig.2 is termed as modification 1 . In this modification, the leading-edge is modified like a saw-tooth which is sharp on the edges. The cut was very small that it does not affect the propeller aerodynamically in a larger scale.

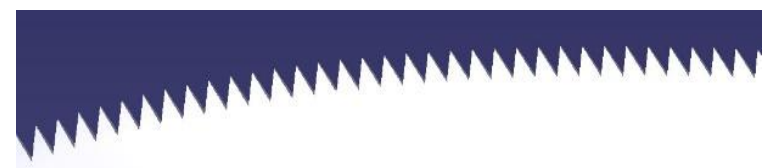

Fig 2.Propeller with saw-tooth cut

\subsection{Modification 2 - Curved Cut}

A curved sharp cut shown in Fig. 3 is termed as modification 2. In this modification, the leading-edge is modified with a curved blunt cut. This curved cut is also very small which will not affect the propeller aerodynamically in a larger scale.

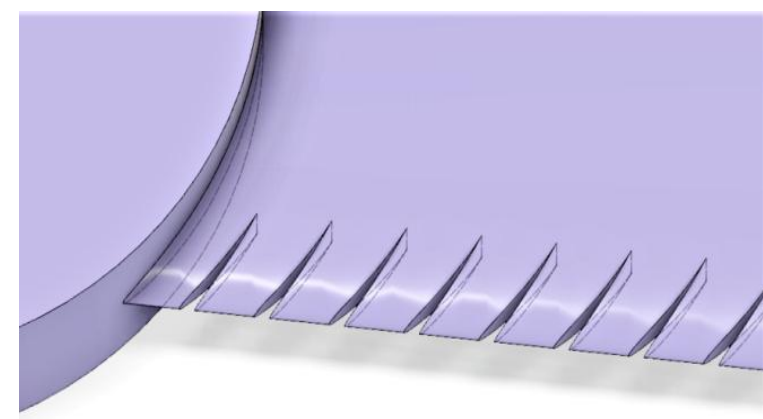

Fig 3.Propeller with curved cut

\subsection{Modification 3 - Part retained Cut}

A part retained cut shown in Fig. 3 is termed as modification 3. In this modification, the upper and lower surface of the propeller is removed in a cured path for certain distance horizontally and a small part is retained in the middle layer of the propeller. The cut is very small in this modification too and it does not affect the propeller aerodynamically in a larger scale.

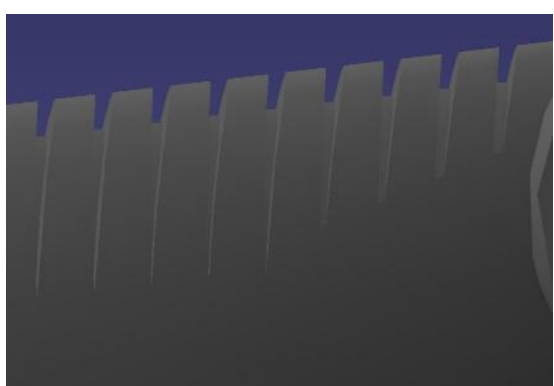

Fig 4. Propeller with retained cut

\section{NUMERICAL SIMULATION \& RESULTS}

Numerical simulation is done with the help of Ansys Fluent workbench 16.2 and the results are listed in table 1. In order to analyse the noise variation on the UAV's, the prime noise-induced rotating component is considered as a reference component. The existing propeller of HQ bull nose $5 \times 4.5 "$ is taken as the base model. After the complete survey, the modifications are included in the base model and thereby three versions are modeled.

\subsection{Results of Normal Propeller}

The acoustic power for the propeller is found to be 22 , $30.4,35.1 \mathrm{~dB}$ for velocities of 10, 13, $15 \mathrm{~m} / \mathrm{s}$ shown in Fig. 5,6 , and 7 respectively for HTOL configuration and the acoustic power for VTOL configuration is found to be 14.2, 20.9, $26.4 \mathrm{~dB}$ in velocities of 8, 10, $12 \mathrm{~m} / \mathrm{s}$ shown in Fig. 8, 9,10 respectively.

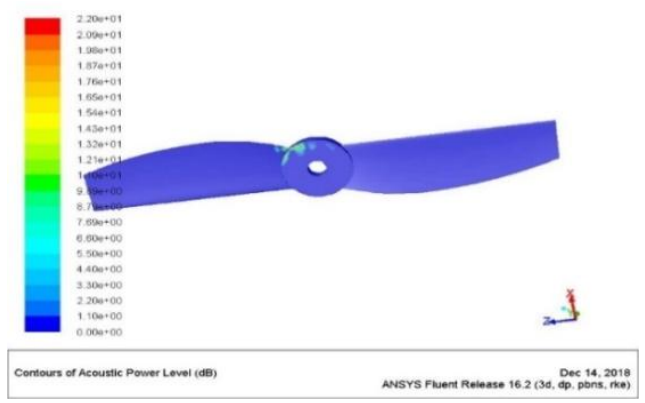

Fig 5.HTOL $-10 \mathrm{~m} / \mathrm{s}$

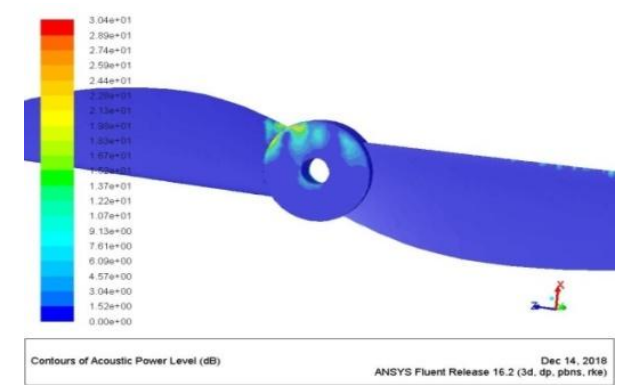

Fig 6.HTOL - 13 m/s

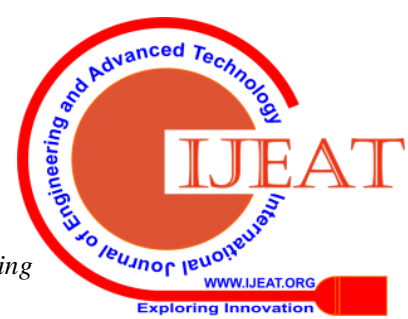




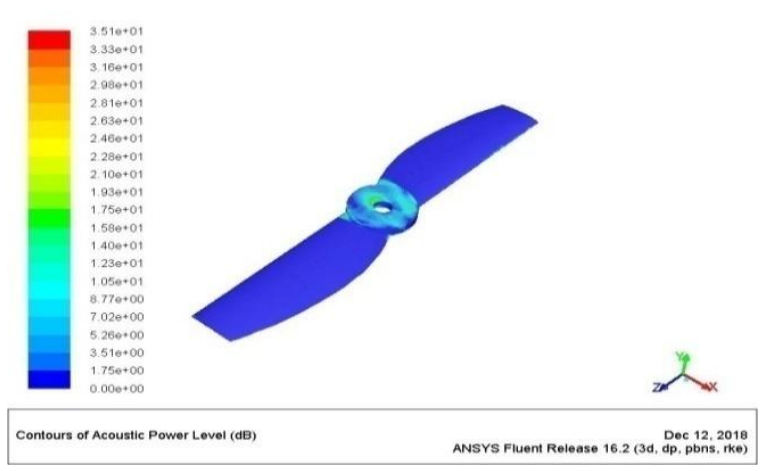

Fig 7.HTOL- $15 \mathrm{~m} / \mathrm{s}$

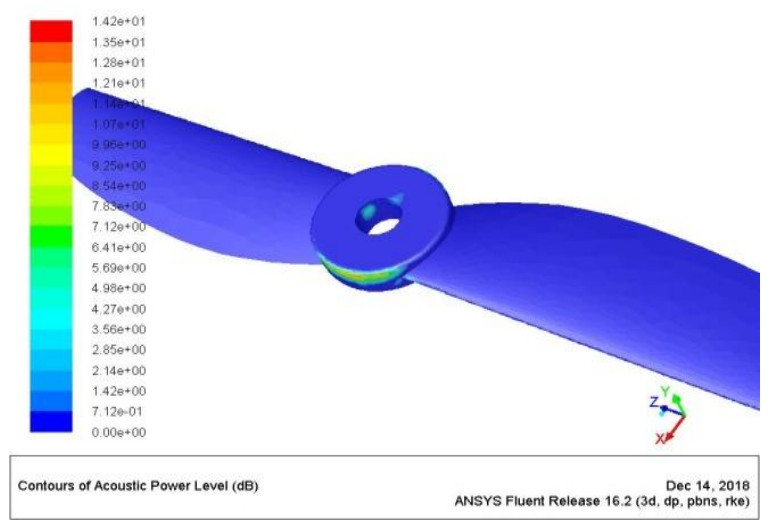

Fig 8. VTOL $-8 \mathrm{~m} / \mathrm{s}$

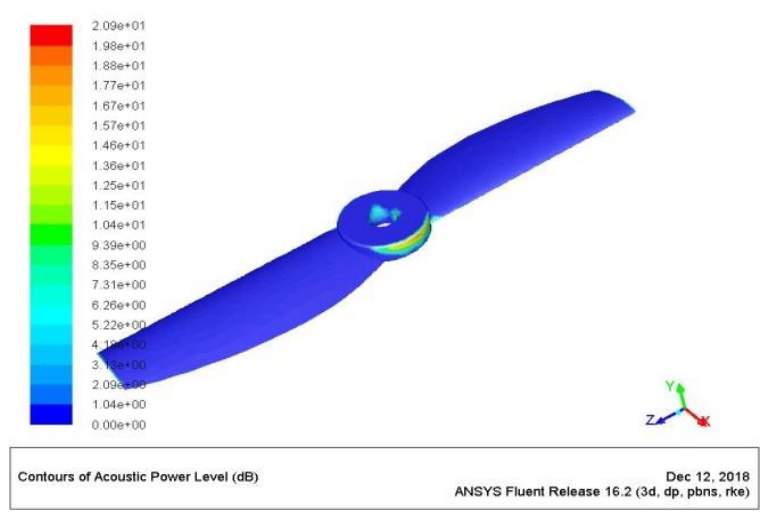

Fig 9. VTOL- $10 \mathrm{~m} / \mathrm{s}$

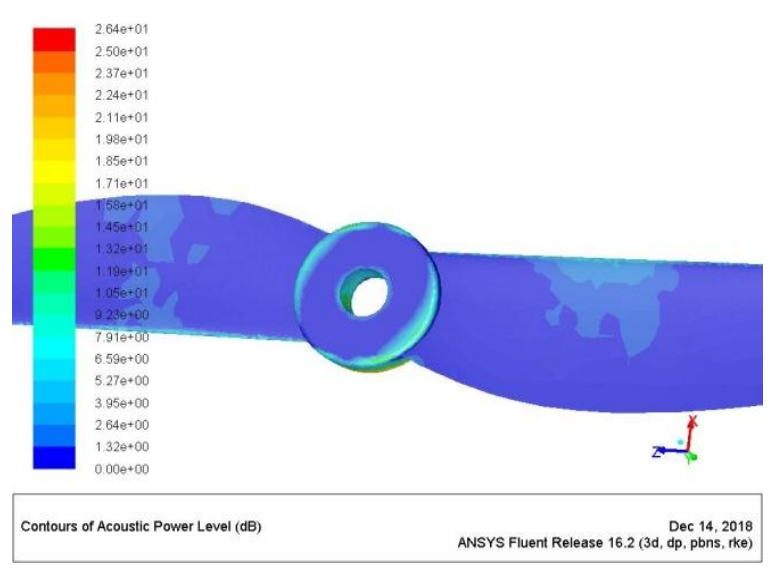

Fig 10.VTOL $12 \mathrm{~m} / \mathrm{s}$ acoustic power in VTOL configuration is found to be 12.1, 18.9, $24.4 \mathrm{~dB}$ in velocities of $8,10,12 \mathrm{~m} / \mathrm{s}$ shown in Fig 14 , 15,16 respectively.

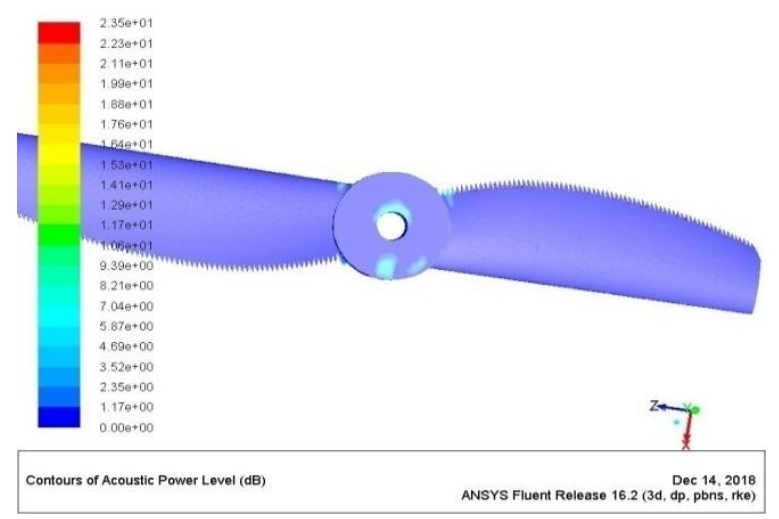

Fig 11. HTOL $-10 \mathrm{~m} / \mathrm{s}$

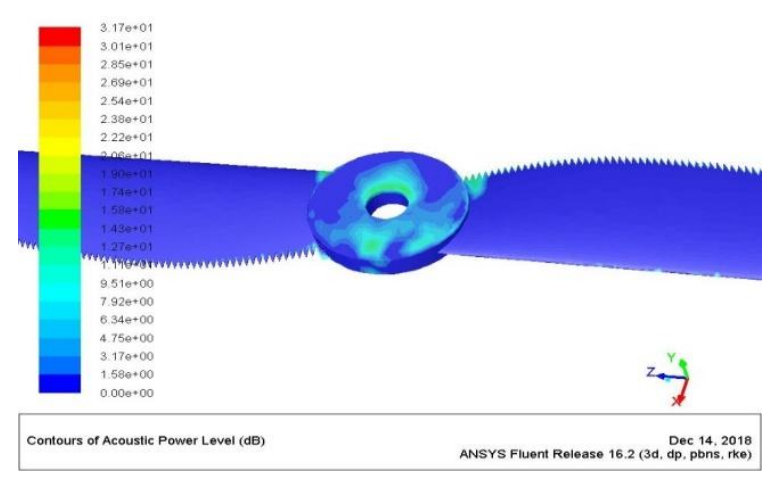

Fig 12. HTOL $-13 \mathrm{~m} / \mathrm{s}$

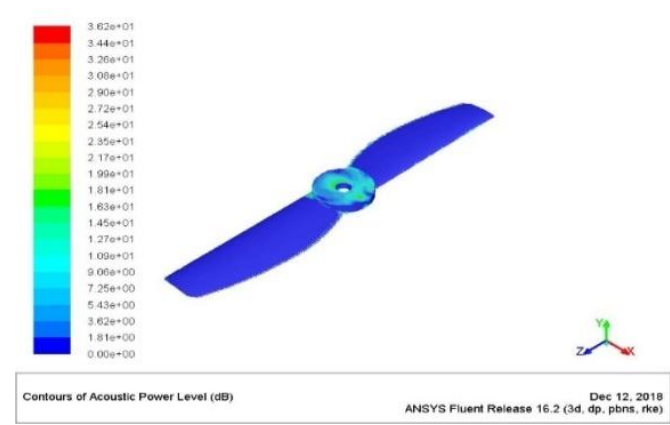

Fig 13. HTOL- 15m/s

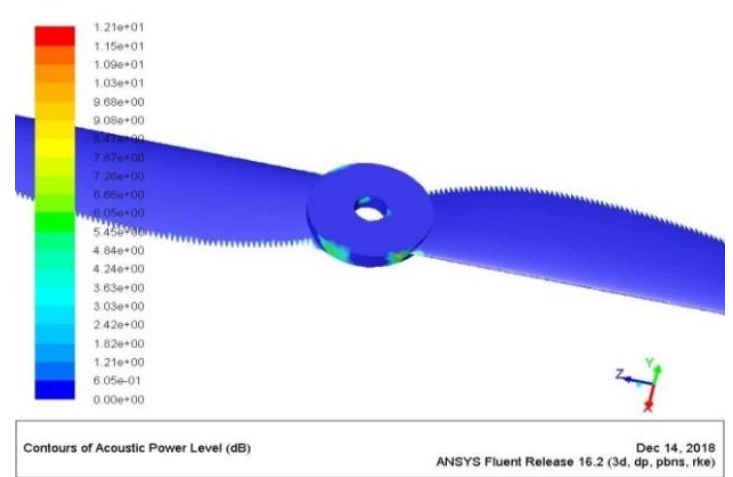

Fig 14. VTOL $-8 \mathrm{~m} / \mathrm{s}$

3.2 Results of Propeller with Modification - 1

The acoustic power for the propeller is found to be 23.5, $31.7,36.2 \mathrm{~dB}$ for velocities of $10,13,15 \mathrm{~m} / \mathrm{s}$ shown in Fig $11,12,13$ respectively for HTOL configuration and the
Published By:

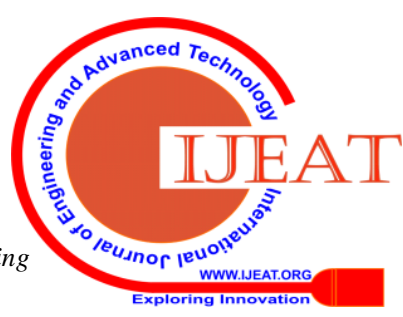




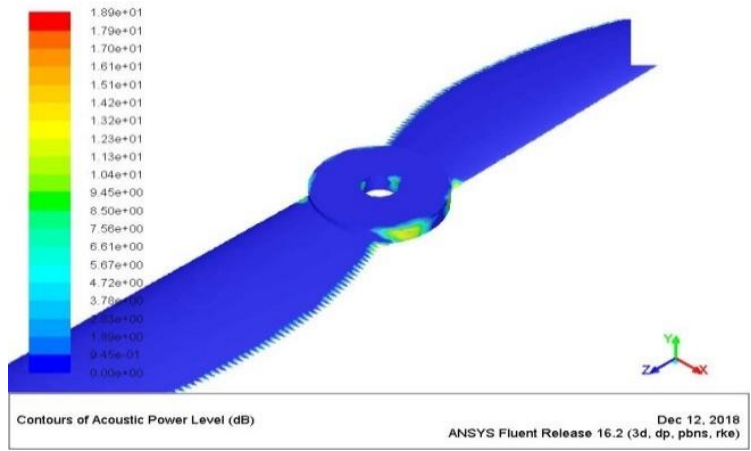

Fig 15. VTOL - 10m/s

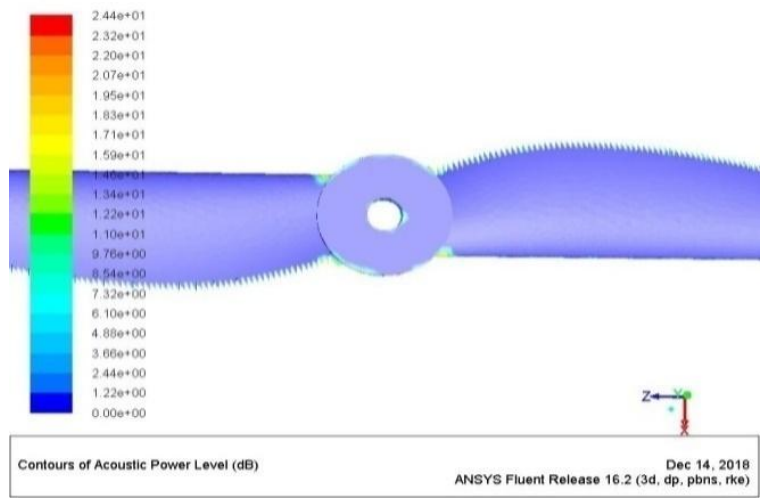

Fig 16. VTOL $-12 \mathrm{~m} / \mathrm{s}$

3.3 Results of Propeller with Modification - 2

The acoustic power for the propeller is found to be 10.9 , 20.1, $24.7 \mathrm{~dB}$ for velocitiesx of 10, 13, $15 \mathrm{~m} / \mathrm{s}$ shown in Fig. 17, 18, 19 respectively for HTOL configuration and the acoustic power in VTOL configuration is found to be 17.9, $28.0,34.3 \mathrm{~dB}$ in velocities of $8,10,12 \mathrm{~m} / \mathrm{s}$ shown in Fig. 20 , 21,22 respectively.

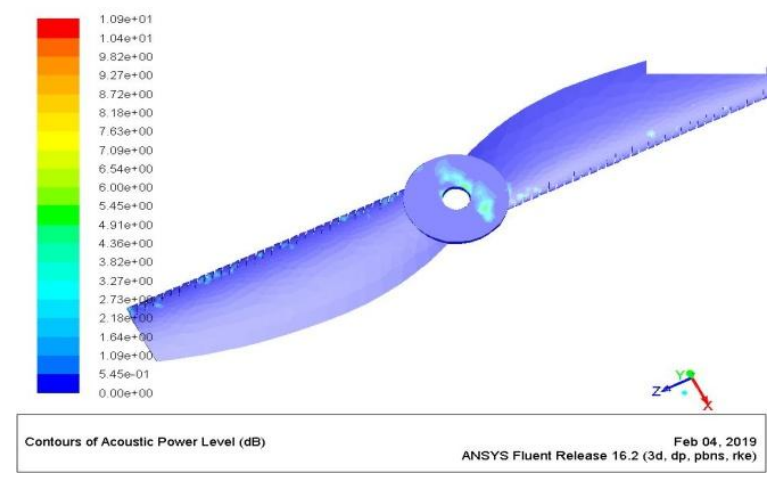

Fig 17. HTOL - $10 \mathrm{~m} / \mathrm{s}$

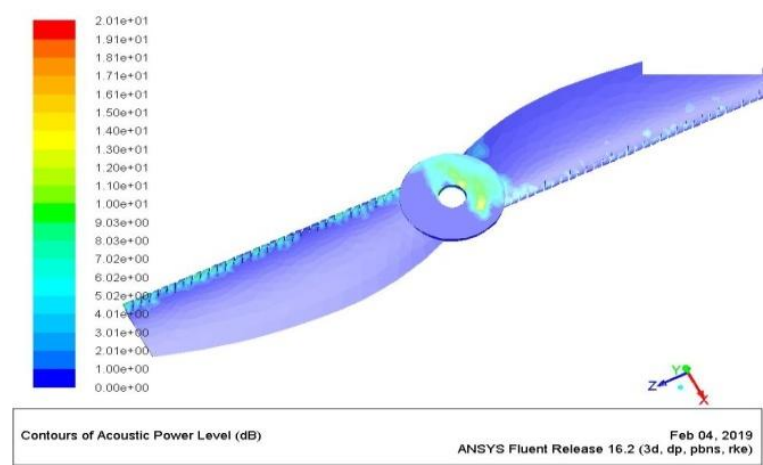

Fig 18. HTOL - $13 \mathrm{~m} / \mathrm{s}$

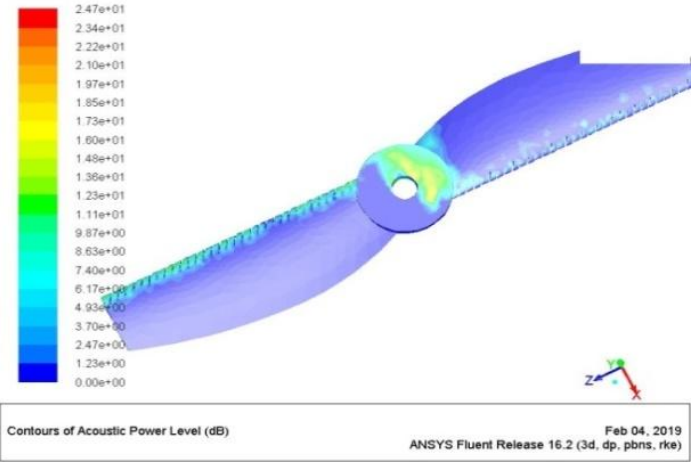

Fig 19. HTOL - $15 \mathrm{~m} / \mathrm{s}$

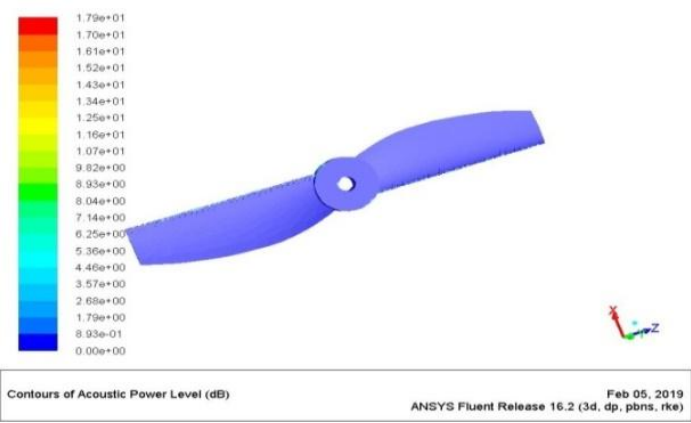

Fig 20. VTOL - $8 \mathrm{~m} / \mathrm{s}$

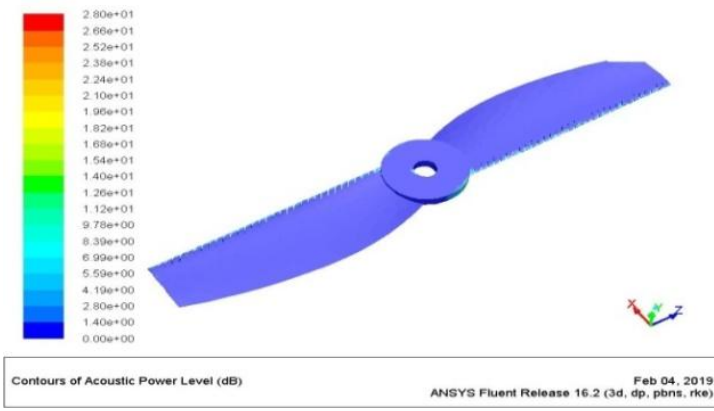

Fig 21. VTOL - $10 \mathrm{~m} / \mathrm{s}$

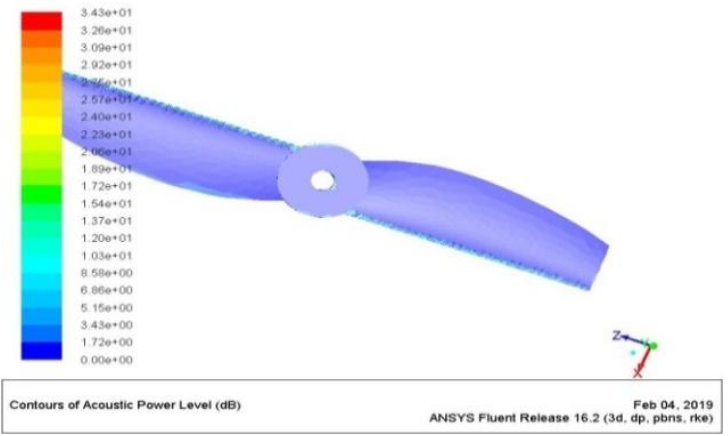

Fig 22. VTOL - $12 \mathrm{~m} / \mathrm{s}$

3.4 Results of Propeller with Modification - 3

The acoustic power for the propeller is found to be 20.5 , $27.9,32.5 \mathrm{~dB}$ for velocities of $10,13,15 \mathrm{~m} / \mathrm{s}$ shown in Fig. 23, 24, 25 respectively for HTOL configuration and the acoustic power in VTOL configuration is found to be 13.1, 20.5, $25.4 \mathrm{~dB}$ in velocities of 8, 10, $12 \mathrm{~m} / \mathrm{s}$ shown in Fig. 26, 27,28 respectively.

\section{Published By:}

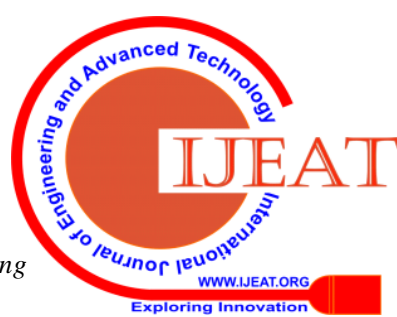




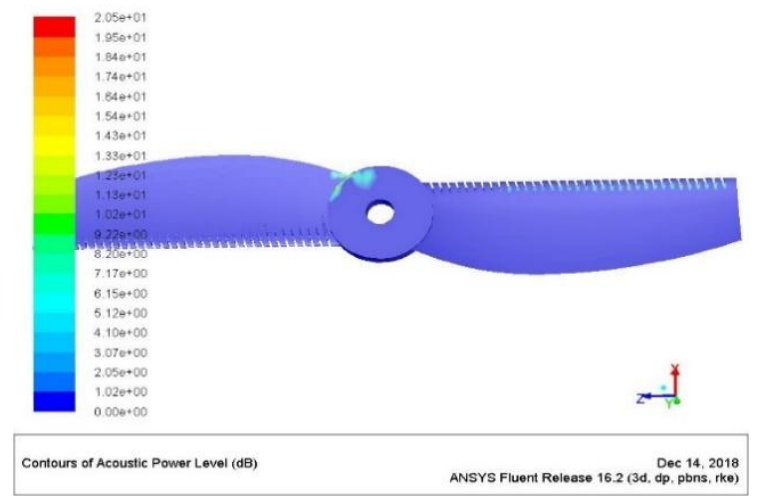

Fig 23. HTOL $-10 \mathrm{~m} / \mathrm{s}$

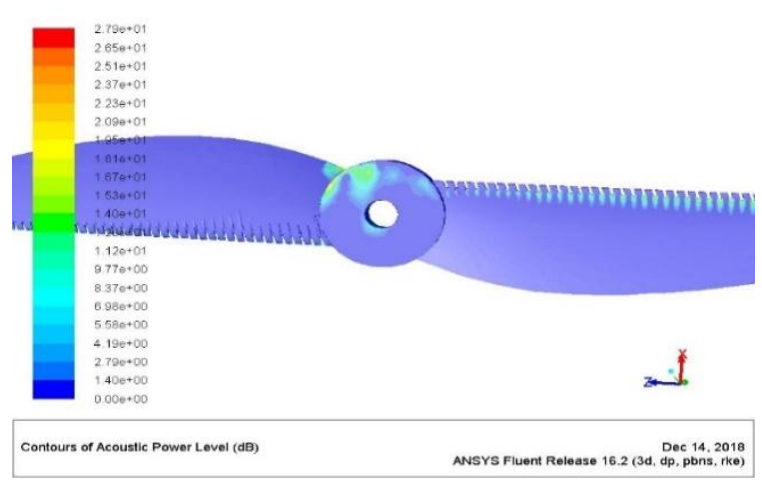

Fig 24. HTOL $-13 \mathrm{~m} / \mathrm{s}$

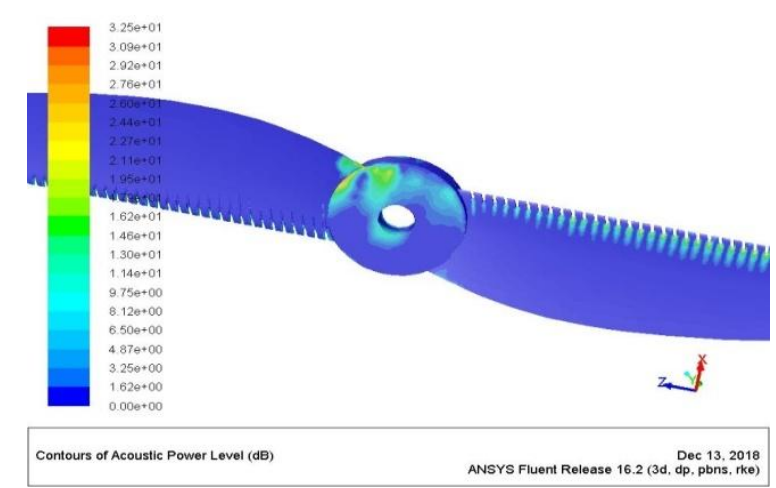

Fig 25. HTOL $-15 \mathrm{~m} / \mathrm{s}$

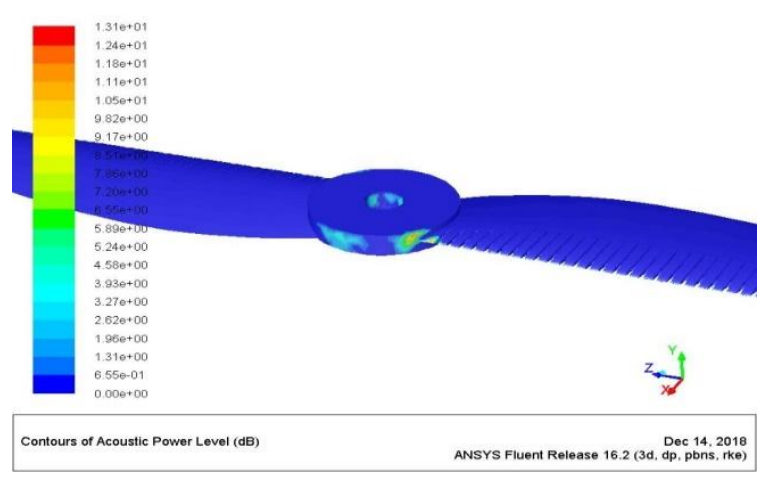

Fig 26. VTOL $-8 \mathrm{~m} / \mathrm{s}$

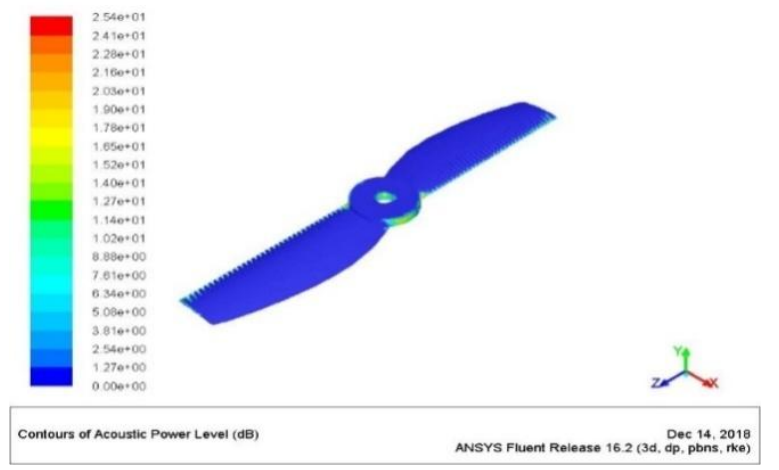

Fig 27. VTOL $-8 \mathrm{~m} / \mathrm{s}$

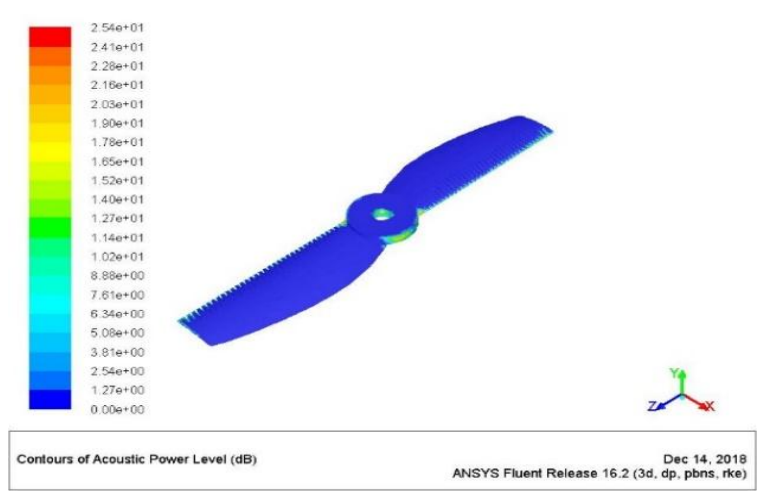

Fig 28. VTOL $-12 \mathrm{~m} / \mathrm{s}$

3.5 Comparative analysis

Table .1 Comparative values of acoustics

\begin{tabular}{|c|c|c|c|c|c|}
\hline Operation & $\begin{array}{c}\text { Velocity } \\
(\mathrm{m} / \mathrm{s})\end{array}$ & $\begin{array}{c}\text { Normal } \\
\text { Propeller }\end{array}$ & Case-1 & Case - 2 & Case - 3 \\
\hline HTOL & 10 & 22 & 23.5 & 10.9 & 20.5 \\
\hline HTOL & 13 & 30.4 & 31.7 & 20.1 & 27.9 \\
\hline HTOL & 15 & 35.1 & 36.2 & 24.7 & 32.5 \\
\hline VTOL & 8 & 14.2 & 12.1 & 19.1 & 13.1 \\
\hline VTOL & 10 & 20.9 & 18.9 & 28.0 & 34.3 \\
\hline VTOL & 12 & 26.4 & 24.4 & 34.3 & 25.4 \\
\hline
\end{tabular}

Boundary conditions play a major role in numerical simulation, which decides the accuracy in the output of the simulation. The numerical simulation results are approximate or acceptable depending on the given boundary conditions. In this case, fluent solver with a viscous model of k-epsilon, Realizable and scalable wall functions, an acoustic model of broadband noise sources with reference acoustic power of $1 \mathrm{e}-08$ with different velocities are used.

\section{CONCLUSIONS}

The designs with leading edge modifications from the base propeller are modeled with the help of CATIA V5. The numerical simulation is carried out using the ANSYS Fluent Workbench 16.2, in which two operations like HTOL and VTOL are analyzed. From this numerical simulation results, it is concluded that the acoustic power values for the propeller with modified leading-edge induces less noise and the propeller with the modification 1 is suitable for VTOL operations as the acoustic values are decreased in all

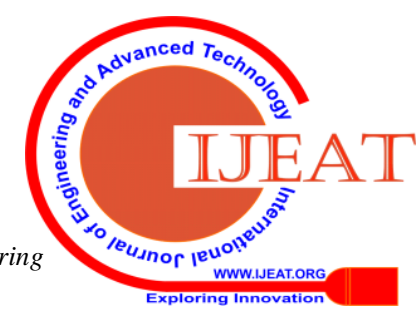


analyzed velocities and propeller with modification 3 is suitable for HTOL operations as the acoustic power values are decreased for all analyzed velocities. The analysis with moving reference frame is the future work of this paper.

\section{REFERENCES}

1. Callender MN (2017) UAS Propeller/Rotor Sound Pressure LevelReduction Through Leading Edge Modification. J Appl Mech Eng 6: 254. doi:10.4172/2168-9873.1000254

2. Vijayanandh R et al., Acoustic Analysis and Comparison of Chevron Nozzle Using Numerical Simulation, International Journal of Mechanical and Production Engineering Research and Development, ISSN(E): 2249-8001, Vol. 8, Special Issue 7, 2018, 1089-1103.

3. Callender MN, Robinson V (2016) Small UAS propeller/rotor sound pressure level and thrust testing: bioinspired modifications for UAS noise reduction. Proceedings of XPonential 2016. New Orleans Association of Unmanned Vehicle Systems International.

4. Vijayanandh R et al., Design, Fabrication and Simulation of Hexacopter for Forest Surveillance, ARPN Journal of Engineering and Applied Sciences, ISSN 1819-6608, VOL. 12, No. 12, 2017, page no $3879-3884$.

5. Clark IA, Alexander WN, Devenport W, Glegg S, Jaworski JW (2015) Bio-inspired trailing edge noise control. Proceedings of the 21st AIAA/CEAS Aeroacoustics Conference Dallas.

6. Vijayanandh R et al., Numerical Study on Structural Health Monitoring for Unmanned Aerial Vehicle, Journal of Advanced Research in Dynamical and Control Systems, Vol. 9. Sp-6/2017, pp 1937 - 1958.

7. Vijayanandh $\mathrm{R}$ et al., Conceptual design and structural analysis of integrated composite Micro Aerial Vehicle, Journal of Advanced Research in Dynamical and Control Systems, Vol. 9. Sp- 14 / 2017, pp 857 - 881 .

8. Lyu B, Azarpeyvand M, Sinayoko S (2015) A trailing-edge noise model for serrated edges. Proceedings 21st AIAA/CEAS Aeroacousitcs ConferenceDallas.

9. Vijayanandh R et al., Design, fabrication of Tilt-Hexacopter with image processing for critical applications, International Journal of Pure and Applied Mathematics Special Issue, Volume 118 No. 9 2018, 935-945, ISSN: 1314-3395

10. Wisniewski CF, Byerley AR, Heiser WH, Liller WR (2015) Experimental evaluation of open propeller aerodynamics performance and aero-acoustic behavior. Proceedings of 33rd AIAA Applied Aerodynamics Conference. Dallas American Institute of Aeronautics and Astronics Inc.

11. Vijayanandh R., Design Optimization of Advanced Multirotor Unmanned Aircraft System Using FSI, Book Title " Innovative Design, Analysis and Development Practices in Aerospace and Automotive Engineering (I-DAD 2018)", Springer Series Title - Lecture Notes in Mechanical Engineering, eBook ISBN - 978-981-13-2718-6, Chapter number 28, DOI 10.1007/978-981-13-2718-6.

12. Crigler, J.L. 1948. application of theodorsen's theory to Propellerdesign. NACA report 924, March 1948.

13. Vijayanandh $\mathrm{R}$ et al., Energy harvesting from a Gas Turbine Engines exhaust heat Using Quantum Well ThermoElectric materials Generator, Materials Today: Proceedings 4 (2017) 8378-8386. 